\title{
A FRAGILIDADE AMBIENTAL DA BACIA HIDROGRÁFICA DO CÓRREGO BOM JARDIM, BRASILÂNDIA/MS.
}

\author{
Gustavo Henrique de Oliveira ${ }^{1}$
}

André Luiz Pinto ${ }^{2}$

\section{Gilberto da Silva Lorencetti ${ }^{3}$}

RESUMO: O presente trabalho visa ressaltar a importância dos estudos em bacias hidrográficas como unidade de estudo físico-paisagísticos compostas por elementos interdependentes capazes de serem mensurados e zoneados. Na bacia do córrego Bom Jardim localizada dentro dos limites municipais de Brasilândia/MS, ocorrem diversos tipos de processos erosivos tanto de âmbito laminar quanto linear que por sua vez transportam sedimentos das vertentes da bacia para o leito de seu canal principal e seus afluentes. Nesse sentido objetivou-se demonstrar a importância da compreensão dos fatores físicos principais constituintes em uma bacia a fim de compará-los e correlacioná-los obtendo assim de forma adaptada os níveis de Fragilidade Potencial e Ambiental ao qual a mesma está sujeita. Faz-se necessário, portanto uma análise sintetizada dos dados advindos de mapeamentos temáticos de Declividade, Solos, Geologia, Pluviometria e áreas especiais denominadas aqui de Áreas de Prioridade Biológica de conservação para uma melhor compreensão da evolução dos diferentes processos geológico-geomorfológicos averiguados na bacia e que afetam a mesma deixando-a com baixos e/ou altos níveis de vulnerabilidade ou fragilidade. O produto final da sintetização desses dados pode servir de base para a construção de um planejamento ou plano de manejo que identifique os processos que afetam o meio físico natural da bacia como um todo.

Palavras-chave: Geoprocessamento; Bacia Hidrográfica; Fragilidade Ambiental.

\footnotetext{
${ }_{1}^{1}$ Bolsista CAPES pelo Programa de Pós-graduação em Geografia UFMS/CPTL, henriqueguo@hotmail.com

${ }^{2}$ Prof. Dr. Associado III no Curso de Geografia da UFMS Campus de Três Lagoas/MS, andre.pinto@ufms.br

${ }^{3}$ Graduando em Ciências Biológicas pela Universidade Paulista - UNIP - gilberto lorencetti@hotmail.com,
} 


\title{
1 INTRODUÇÃO
}

Após o estabelecimento da bacia hidrográfica como unidade de estudo e de planejamento, pela Agência Nacional de Águas, é crescente o número de pesquisadores que as adotam como recorte espacial para diagnóstico, análise e prognóstico. A grande vantagem que se encontra nesse âmbito está nas possibilidades de inter-relações entre os vários subsistemas que a constituem. Nesse sentido a bacia hidrográfica deve ser considerada como unidade básica de gestão dos recursos hídricos.

\begin{abstract}
A bacia hidrográfica, através da rede de drenagem fluvial, integra grande parte das relações causa-efeito que devem ser tratadas na gestão. Embora existam outras unidades político administrativas a serem consideradas, como os municípios, estados, regiões e países, essas unidades não apresentam necessariamente o caráter integrador da bacia hidrográfica, o que poderia tornar a gestão parcial e ineficiente caso fossem adotadas (SRH/MMA, 1997).
\end{abstract}

O dinamismo encontrado nos sistemas de bacias hidrográficas reflete de maneira extremamente simplificada as complexas interferências e correlações entre os elementos dos subsistemas naturais, construídos, socioeconômicos e produtivos, e a crescente interferência antrópica.

Ross (1994) afirma que:

\begin{abstract}
A fragilidade dos ambientes naturais face as intervenções humanas é maior ou menor em função de suas características genéticas. A princípio, salvo algumas regiões do planeta, os ambientes naturais mostram-se ou mostravam-se em estado de equilíbrio dinâmico até o momento em que as sociedades humanas passaram progressivamente a intervir cada vez mais intensamente na exploração dos recursos naturais. (ROSS, 1994, p. 01)
\end{abstract}

Decorrente dessa preocupação e com o objetivo de auxiliar no ordenamento sustentável do território da bacia do Córrego Bom Jardim, em Brasilândia - MS o objetivo do presente trabalho é avaliar ambientalmente a Fragilidade Potencial da bacia constituída da combinação de informações espaciais Pedológicas, Geomorfológicas, Climáticas, Geológicas e Biológicos (Áreas Prioritárias para a Conservação, Uso Sustentável e Repartição de Benefícios da Biodiversidade Brasileira).

Pretende-se, portanto, através de uma análise integrada ambiental dessas mesmas informações, contribuir, não apenas para com a bacia do córrego Bom Jardim, como 
também subsidiar como referencial teórico metodológico para novos estudos, que visem um ordenamento preventivo do uso da terra pautado em dados distintos, mas de extrema importância nos estudos de bacias e consecutivamente, a redução da perda de solo, produção, produtividade e da qualidade/quantidade de suas águas e melhoria da qualidade ambiental e de vida de seus habitantes.

Brasilândia está localizada na costa leste do estado do Mato Grosso do Sul, tendo como divisa ao norte o município de Três Lagoas e Água Clara, ao sul Santa Rita do Pardo e a leste com o rio Paraná que delimita a fronteira com o estado de São Paulo.

O município possui uma área de aproximadamente $5.000 \mathrm{Km}^{2}$, e situa-se entre as coordenadas geográficas $20^{\circ} 45^{\prime}$ e $21^{\circ} 34^{\prime}$ de latitude S e $51^{\circ} 51^{\prime}$ e $52^{\circ} 56^{\prime}$ de longitude W, sendo essa uma região drenada por inúmeras micro-bacias que fluem para o Rio Paraná (PINTO, 2010).

O clima no município de Brasilândia possui duas estações bem definidas, uma estação chuvosa e outra seca, que segundo a classificação de Koppen é o Aw, definido como clima tropical úmido.

A bacia por sua vez compreende-se por estar localizada em um meio físico ímpar, pois, suas nascentes encontram-se dentro da reserva indígena dos Ofayé-Xavante em meio a uma paisagem preservada por se tratar de uma reserva. Sua foz é marcada pela delimitação da Reserva Particular do Patrimônio Natural - RPPN Cisalpina da CESP (Companhia Energética de São Paulo) que por se tratar de um relevo moderadamente plano acabou por ser inundado devido à construção da UHE de Porto Primavera.

\section{METODOLOGIA}

A carta base e de localização (Figura 01) da bacia foi elaborado com orientações das cartas topográficas da área de estudo. Esse documento constituiu-se no documento passível de mensuração e que serviu de base para a elaboração das cartas subseqüentes, ou seja, de Declividade, Pedológica, Geológica, Pluviométrica, de Áreas de Prioridade Biológica, Fragilidade Potencial e por fim a de Fragilidade Ambiental.

Portanto na elaboração da carta de base da bacia do córrego Bom Jardim, foram utilizadas as cartas topográficas do DSG, folha Brasilândia (SF. 22. V.D. I) e folha Dracena (SF.22.V.D.II), na escala de 1:100.000, que tiveram sua primeira impressão em 
1973, e foram geradas a partir da restituição de fotografias aéreas de 1966, na escala de 1:60.000, posteriormente o mesmo passou por uma atualização a partir de imagens de satélite ortorretificadas NASA (2006).

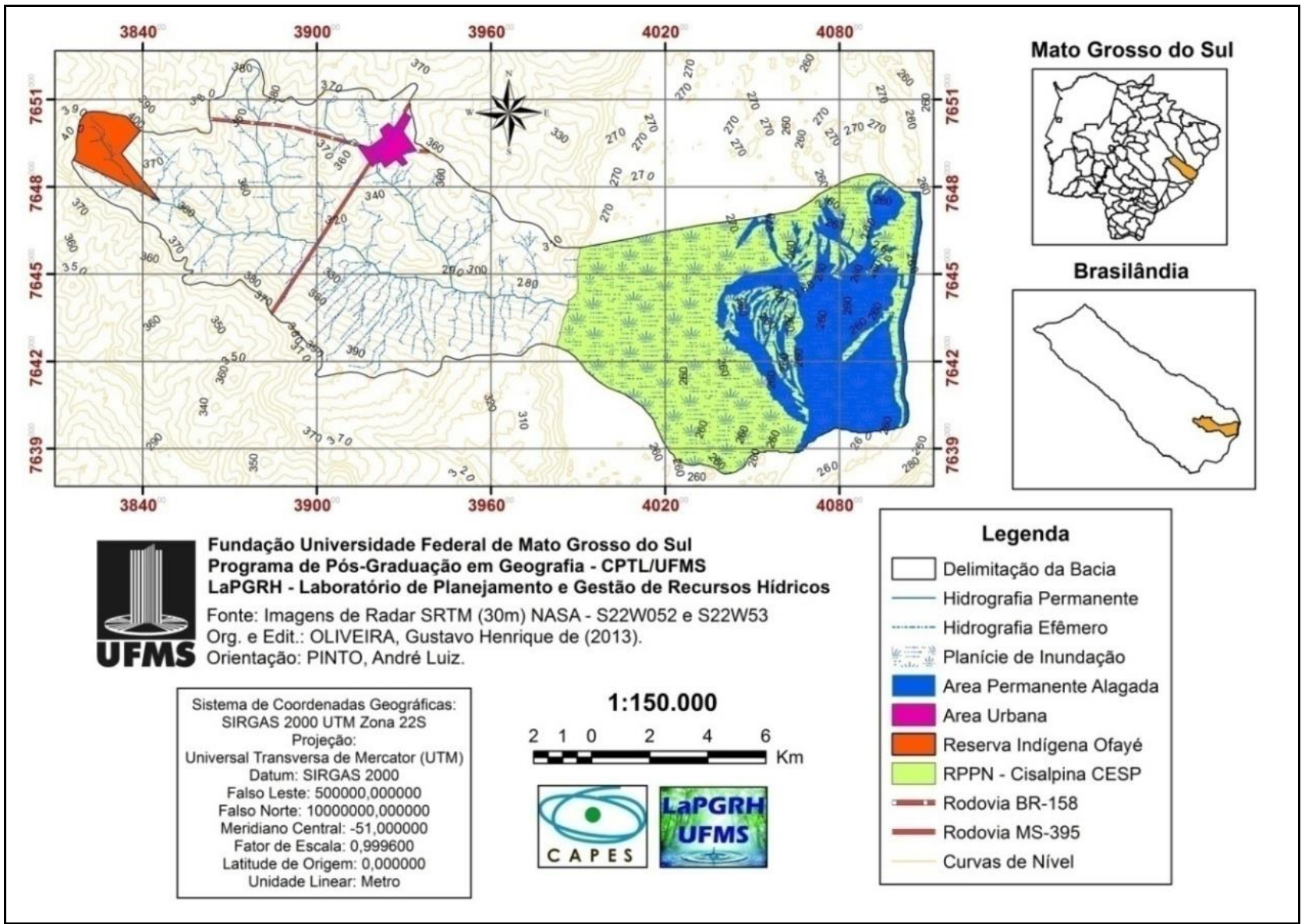

Figura 01: Carta Base e de Localização da Bacia do Córrego Bom Jardim em Brasilândia/MS.

Para alcançar o objetivo proposto foi utilizada no decorrer da metodologia uma adaptação de duas propostas metodológicas: Análise Empírica da Fragilidade dos Ambientes Naturais elaborada por Ross (1994) e na metodologia proposta por Crepani et al.,(2001) denominada Sensoriamento Remoto e Geoprocessamento aplicado ao Zoneamento Ecológico Econômico e ao Ordenamento Territorial, onde acrescentou-se as áreas de Importância biológica, reconhecidas pelo Decreto no. 5092, de 21 de maio de 2004 e instituídas pela Portaria oㅜ 126 de 27 de maio de 2004 do Ministério do Meio Ambiente (MMA) como "Áreas Prioritárias para a Conservação, Uso Sustentável e Repartição de Benefícios da Biodiversidade Brasileira".

A Declividade é o ângulo de inclinação da superfície local em relação ao plano 
horizontal. A modelagem numérica de terreno foi realizada com base em um Modelo de Grade Regular Retangular (MGRR), segundo procedimentos descritos em (CÂMARA et al., 2007). Do modelo foi extraído um Modelo Tridimensional do Relevo, que deu origem os dados de declividade elaborados segundo intervalos de fragilidade estabelecidos por Ross (1994), que correlacionam classes de declividades e seus respectivos níveis de fragilidade potencial.

Para a confecção do mapa de Solos foi realiza a identificação das unidades pedológicas que teve como base o levantamento de solos elaborado pelo Macrozoneamento (RADAM BRASIL, 1984/1985) produzido na escala de 1:250.000, extraído do banco de dados Sistema Interativo de Suporte ao Licenciamento Ambiental (SISLA), (disponível em http://sisla.imasul.ms.gov.br/sisla). A padronização da nomenclatura foi realizada segundo o Sistema Brasileiro de Classificação de Solos (EMBRAPA, 2006).

Para a elaboração da carta Pluviométrica foi feita uma variabilidade espacial da pluviosidade elaborada a partir de médias anuais pluviométricas disponíveis entre os anos de 1970 a 2007. Utilizou-se dados de chuva $(\mathrm{mm})$ de 4 estações meteorológicas da Agência Nacional das Águas (ANA), (disponível em http://www.cpao.embrapa.br/clima/).

Para espacialização da pluviosidade empregou-se o método de interpolação, denominado Inverso do Quadrado da Distância (IQD) ou The Inverse Distance Weighted (IDW), que é um interpolador determinístico univariado de médias ponderadas. A interpolação pelo IQD supõe explicitamente que as feições mais próximas são mais semelhantes do que as mais separadas.

A partir dos valores obtidos de intensidades pluviométricas e suas relações com a vulnerabilidade à perda de solo foi elaborada uma adaptação metodológica com base numa regra de três simples entre os valores máximo de vulnerabilidade à perda de solo (Crepani et al., 2001) e os graus de fragilidade definidos por Ross (1994).

A maior importância da intensidade pluviométrica é facilmente verificada quando se observa que uma elevada pluviosidade anual, mas com distribuição igual ao longo de todo período, isso tem um poder erosivo muito menor do que uma precipitação anual mais reduzida que se despeja torrencialmente num período determinado do ano (CREPANI et al., 2001).

Para obtenção da Prioridade Biológica que na área que recobre a bacia do córrego 
Bom Jardim não existe mapeamento prévio dessa temática, porém assim mesmo foi feita uma adaptação para essa ultima carta temática evidenciando as APPs (Áreas de Preservação Permanente), Reservas Indígena (Comunidade Indígena Ofayé-Xavante) e de Patrimônio Particular Natural (RPPN - CISALPINA/CESP).

Para a elaboração da carta síntese de fragilidade potencial foram aplicados os métodos de combinação de mapas (álgebra de campo), por meio de sobreposição ponderada, disponível no ArcGIS $10 \AA$. Inicialmente foi feita a conversão dos dados vetoriais para a estrutura matricial (formato Grid.) e posteriormente a reclassificação, por meio da ferramenta Spatial Analyst/Reclassify. Em seguida, as etapas percorridas foram as seguintes: Spatial Analyst Tools/Overlay/Weighted Overlay.

A partir do cruzamento dos dados obtidos com a carta síntese de Fragilidade Potencial com os dados de Uso e Ocupação da terra do ano de 2012, foi possível a confecção da carta de Fragilidade Ambiental.

O quadro 01 mostra os graus de fragilidade Potencial (produto obtido através do cruzamento dos dados de mapeamento Clinométrico, Pedológico, Geológico, Pluviométrico e de Prioridades Biológicas de Preservação) e Ambiental (produto resultante do cruzamento dos dados do mapeamento de Fragilidade Potencial com os dados de Uso e Ocupação da terra) e seus pesos segundo a metodologia de Ross, 1994, essa metodologia foi adaptada para a bacia do córrego Bom Jardim.

Quadro 01: Fragilidade Potencial e Ambiental adaptado de Ross, 1994.

\begin{tabular}{|c|l|c|}
\hline $\begin{array}{c}\text { Cores } \\
\text { Temáticas }\end{array}$ & \multicolumn{1}{|c|}{ Graus de Fragilidade } & Peso \\
\hline & Muito Baixo & 1 \\
\hline & Baixo & 2 \\
\hline & Médio & 3 \\
\hline & Alto & 4 \\
\hline & Muito Alto & 5 \\
\hline
\end{tabular}

Fonte: Ross, 1994.

\section{RESULTADOS E DISCUSSÃO}

Segundo Mendonça (1999) a identificação e análise da hipsometria da bacia hidrográfica possibilitam a observação da variação altimétrica do relevo da área, fato 
importante na análise de processos relativos à dinâmica de uso e ocupação e da formação de microambientes da mesma, dentre outros.

A Declividade gerada a partir das imagens SRTM de 90m, apresentou 10 classes de declividades variando entre 0 a 29,15\% de declividade como mostra a tabela 01 que quantifica e qualifica cada classe segundo Ross (1994).

Tabela 01: Declividade da Bacia do Córrego Bom Jardim, Brasilândia/MS e sua

Correlação com os Graus de Fragilidade Potencial adaptados de Ross (1994).

\begin{tabular}{|c|c|c|c|c|c|}
\hline $\begin{array}{l}\text { Cores } \\
\text { Temáticas }\end{array}$ & $\begin{array}{c}\text { Classes de } \\
\text { Declividade (\%) }\end{array}$ & $\mathrm{Km}^{2}$ & $\%$ na bacia & $\begin{array}{c}\text { Fragilidade } \\
\text { Potencial }\end{array}$ & Peso \\
\hline & 0 a 1 & 79,42 & 40,97 & \multirow{4}{*}{ Muito Baixa } & \multirow{4}{*}{1} \\
\hline & $1 \mathrm{a} 2$ & 5,73 & 2,96 & & \\
\hline & 2 a 3 & 0,02 & 0,01 & & \\
\hline & $3 a 6$ & 79,21 & 40,86 & & \\
\hline & 6 a 9 & 15,78 & 8,14 & \multirow{2}{*}{ Baixa } & \multirow{2}{*}{2} \\
\hline & 9 a 12 & 12 & 6,19 & & \\
\hline & 12 a 15 & 1,24 & 0,64 & \multirow{2}{*}{ Média } & \multirow{2}{*}{3} \\
\hline & 15 a 20 & 0,38 & 0,20 & & \\
\hline & 20 a 25 & 0,07 & 0,04 & \multirow{2}{*}{ Alta } & \multirow[b]{2}{*}{4} \\
\hline & 25 a 29,15 & 0,01 & 0,01 & & \\
\hline & DTAL & 193,86 & 100,00 & & \\
\hline
\end{tabular}

Organização: Oliveira, 2013.

Fonte: Adaptado de Ross (1994).

No que refere-se à Pedologia da bacia podemos analisar que existem somente três tipos diferentes de solos (Tabela 02), sendo que o de maior destaque mostrou ser um solo extremamente hidromórfico e permanentemente inundado por se espacializar numa planície de inundação recobrindo toda a foz e baixo curso da bacia.

Tabela 02: Tipos de solo encontrados na bacia do córrego Bom Jardim, Brasilândia/MS.

\begin{tabular}{c|l|c|c|c|c}
\hline Legenda & \multicolumn{1}{|c|}{ Tipos de Solo Área } & $\begin{array}{c}\text { Área } \\
(\mathbf{K m})\end{array}$ & $\begin{array}{c}\text { Fragilidade } \\
\text { Potencial }\end{array}$ & Pesos \\
\hline LEa9 & $\begin{array}{l}\text { Latossolo Vermelho-Escuro álico A } \\
\text { moderado textura média e argilosa } \\
\text { relevo plano e suave ondulado }\end{array}$ & 22,85 & 11,72 & Baixa & 2 \\
\hline AC2 & $\begin{array}{l}\text { Área de Solo hidromórfico } \\
\text { periódicamente inundado. }\end{array}$ & 90,13 & 46,25 & Muito Alta & 5 \\
\hline LEa22 & $\begin{array}{l}\text { Latossolo Vermelho-Escuro álico A } \\
\text { moderado textura média }\end{array}$ & 81,88 & 42,03 & Média & 3 \\
\hline
\end{tabular}

Org.: Oliveira, 2013.

Fonte: Adaptado de Ross (1994). 
A carta Geológica da bacia dispôs-se dos seguintes dados resultantes na tabela 03, onde foram encontradas as formações geológicas Santo Anastácio $(22,38 \%)$ que recobre as áreas do alto curso abrangendo as nascentes do canal principal e de seus dois afluentes, Caiuá $(31,64 \%)$ no médio curso da bacia e Depósitos Aluvionares $(89,14 \%)$ dispostos em toda a área do baixo curso onde está localizada a RPPN Cisalpina.

Tabela 03: Disposição Geológica da Bacia do Córrego Bom Jardim, Brasilândia/MS.

\begin{tabular}{c|l|r|c|c|c}
\hline $\begin{array}{c}\text { Cores } \\
\text { Temáticas }\end{array}$ & Formação Geológica & \multicolumn{1}{c}{$\begin{array}{c}\text { Área } \\
\left(\mathbf{K m}^{2}\right)\end{array}$} & \multicolumn{1}{c|}{$\begin{array}{c}\text { Área } \\
\mathbf{( \% )}\end{array}$} & $\begin{array}{c}\text { Fragilidade } \\
\text { Potencial }\end{array}$ & Pesos \\
\hline & Santo Anastácio & 43,39 & 22,38 & Baixa & 2 \\
\hline & Caiuá & 61,33 & 31,64 & Média & 3 \\
\hline & Despósitos Aluvionares & 89,14 & 45,98 & Muito Alta & 5 \\
\hline & TOTAL & 193,86 & 100 & & \\
\hline
\end{tabular}

Org.: Oliveira, 2013.

Fonte: Adaptado de Ross (1994).

A precipitação encontrada na bacia varia entre $1.285,28 \mathrm{~mm}$ na área do alto curso a 1.188,00 mm no baixo curso, mostrando assim uma variação de 97,28 mm do alto curso para o baixo curso. A intensidade pluviométrica encontrada para a área da bacia do córrego Bom Jardim, foi obtida a partir dos dados interpolados das estações meteorológicas localizadas no próprio município (estação Porto Galeano) e municípios vizinhos: Bataguassu (estação Porto Uerê) e Três Lagoas (estações Jupiá e FENOB). (Tabela 04)

Tabela 04: Dados referentes à localização das estações meteorológicas e sua correlação com a precipitação adaptado de Crepani (2001) e Ross (1994).

\begin{tabular}{l|l|r|r|c|c}
\hline $\begin{array}{c}\text { Nome da } \\
\text { Estação }\end{array}$ & Município & \multicolumn{1}{c|}{$\begin{array}{c}\text { Localização } \\
\text { Geográfica }\end{array}$} & $\begin{array}{c}\text { Precipitação } \\
\text { Media Anual } \\
(\mathbf{m m})\end{array}$ & $\begin{array}{c}\text { Fragilidade } \\
\text { Potencial }\end{array}$ & Pesos \\
\hline Porto Galeano & Brasilândia & $\begin{array}{l}52^{\circ} 09^{\prime} 35^{\prime \prime} \mathrm{W} \\
21^{\circ} 05^{\prime} 35^{\prime \prime} \mathrm{S}\end{array}$ & $1.317,20$ & Baixa & 2 \\
\hline FENOB & Três Lagoas & $\begin{array}{l}51^{\circ} 42^{\prime} 59^{\prime \prime} \mathrm{W} \\
20^{\circ} 47^{\prime} 59^{\prime \prime} \mathrm{S}\end{array}$ & 831,50 & Baixa & 2 \\
\hline Porto Uerê & Bataguassu & $\begin{array}{l}52^{\circ} 08^{\prime}, 17^{\prime \prime} \mathrm{W} \\
21^{\circ} 53^{\prime} 29^{\prime \prime} \mathrm{S}\end{array}$ & $1.304,40$ & Baixa & 2 \\
\hline Jupiá & Três Lagoas & $\begin{array}{l}51^{\circ} 30^{\prime} 54^{\prime \prime} \mathrm{W} \\
20^{\circ} 50^{\prime} 06^{\prime \prime} \mathrm{S}\end{array}$ & $1.207,30$ & Baixa & 2 \\
\hline
\end{tabular}

Fonte: Embrapa (2013). 
A Prioridade Biológica que na área que recobre a bacia do córrego Bom Jardim não existe mapeamento prévio dessa temática, porém assim mesmo foi feita uma adaptação para essa ultima carta temática evidenciando as APPs (Áreas de Preservação Permanente), Reservas Indígena (Comunidade Indígena Ofayé-Xavante) e de Patrimônio Particular Natural (RPPN - CISALPINA/CESP).

A carta de Prioridade Biológica da bacia foi elaborada seguindo uma adaptação, onde os temas abordados neste mapeamento seguiram os seguintes critérios da tabela 05. Desta forma foi possível atribuir pesos para as diferentes áreas espacializadas tidas como de uso prioritário para conservação biológica.

Tabela 05: Espacialização e classificação da Fragilidade Potencial das áreas de Prioridade Biológica da bacia.

\begin{tabular}{l|c|c}
\hline \multicolumn{1}{c|}{$\begin{array}{c}\text { Prioridade } \\
\text { Biológica }\end{array}$} & $\begin{array}{c}\text { Fragilidade } \\
\text { Potencial }\end{array}$ & Pesos \\
\hline Área com ou Destinada às Áreas de Preservação Permanente $(30 \mathrm{~m})$ & Muito Alta & 5 \\
\hline Área com ou Destinada às Áreas de Preservação Permanente $(15 \mathrm{~m})$ & Muito Alta & 5 \\
\hline Reserva Indígena Ofayé-Xavante & Muito Alta & 5 \\
\hline Reserva Particular do Patrimônio Natural & Muito Alta & 5 \\
\hline Outros tipos de uso da terra na bacia & Baixa & 2 \\
\hline
\end{tabular}

Org.: Oliveira, 2013.

Fonte: Adaptado de Ross (1994).

A partir da combinação de dados de declividade, solos, geologia, pluviometria e prioridade biológica, foi possível caracterizar a Bacia Hidrográfica do Córrego Bom Jardim em 3 graus de fragilidade: Baixa, Média e Alta. (Figura 02) 


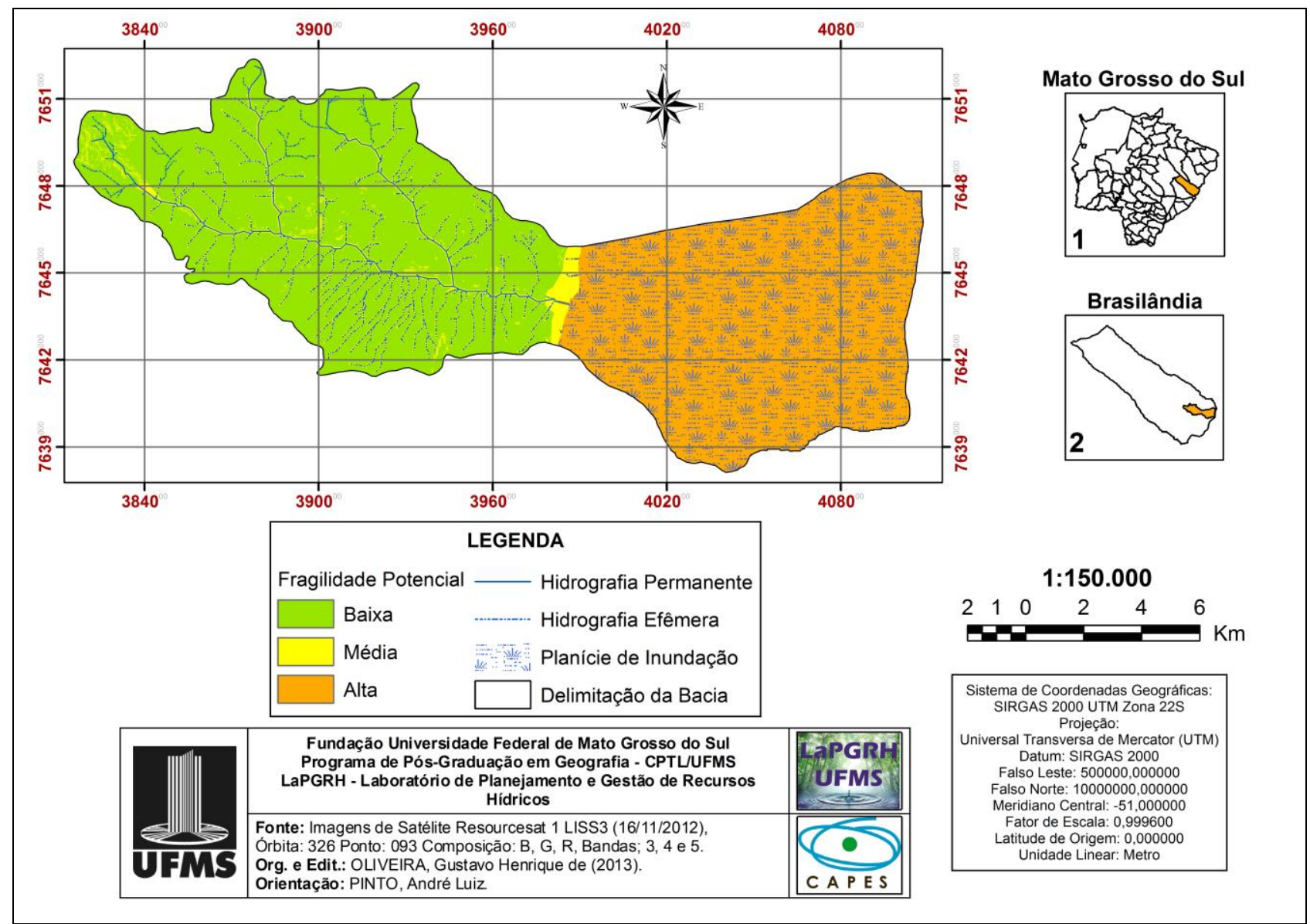

Figura 02: Carta de Fragilidade Potencial da Bacia Hidrográfica do Córrego Bom Jardim, Brasilândia/MS.

O quadro 02 mostra os níveis de Fragilidade Potencial da carta de Fragilidade Potencial encontrados na bacia e suas respectivas áreas em quilômetros quadrados $\left(\mathrm{Km}^{2}\right)$ e porcentagem (\%).

Quadro 02: Fragilidade Potencial da Bacia Hidrográfica do Córrego Bom Jardim, Brasilândia/MS.

\begin{tabular}{|c|l|r|r|c|}
\hline Cor & Fragilidade Potencial & Área $\mathbf{( K m}^{2} \mathbf{)}$ & Área (\%) & Pesos \\
\hline & Muito Baixa & 0 & 0 & 1 \\
\hline & Baixa & 90,72 & 46,80 & 2 \\
\hline & Média & 15,01 & 7,74 & 3 \\
\hline & Alta & 88,13 & 45,46 & 4 \\
\hline & Muito Alta & 0 & 0 & 5 \\
\hline \multicolumn{2}{|c|}{ Total } & 193,86 & 100,00 & \\
\hline
\end{tabular}

Org.: Oliveira (2013).

Fonte: Adaptado de Ross (1994). 
A Fragilidade Potencial da bacia de modo geral divide-se evidentemente em duas grandes partes classificadas como Baixa Fragilidade, com $90,72 \%$ da bacia e Alta Fragilidade $(88,13 \%)$.

A carta de Uso e Ocupação da terra do ano de 2012 (Figura 03) mostra a distribuição dos diferentes tipos de uso que ocorrem na bacia, dentre os quais valem ser citados os que nela utilizam-se de praticas preventivas ou conservacionistas como no caso da Cana de açúcar e da Silvicultura onde fica expressamente visível o grande crescimento desses dois tipos de agriculturas.

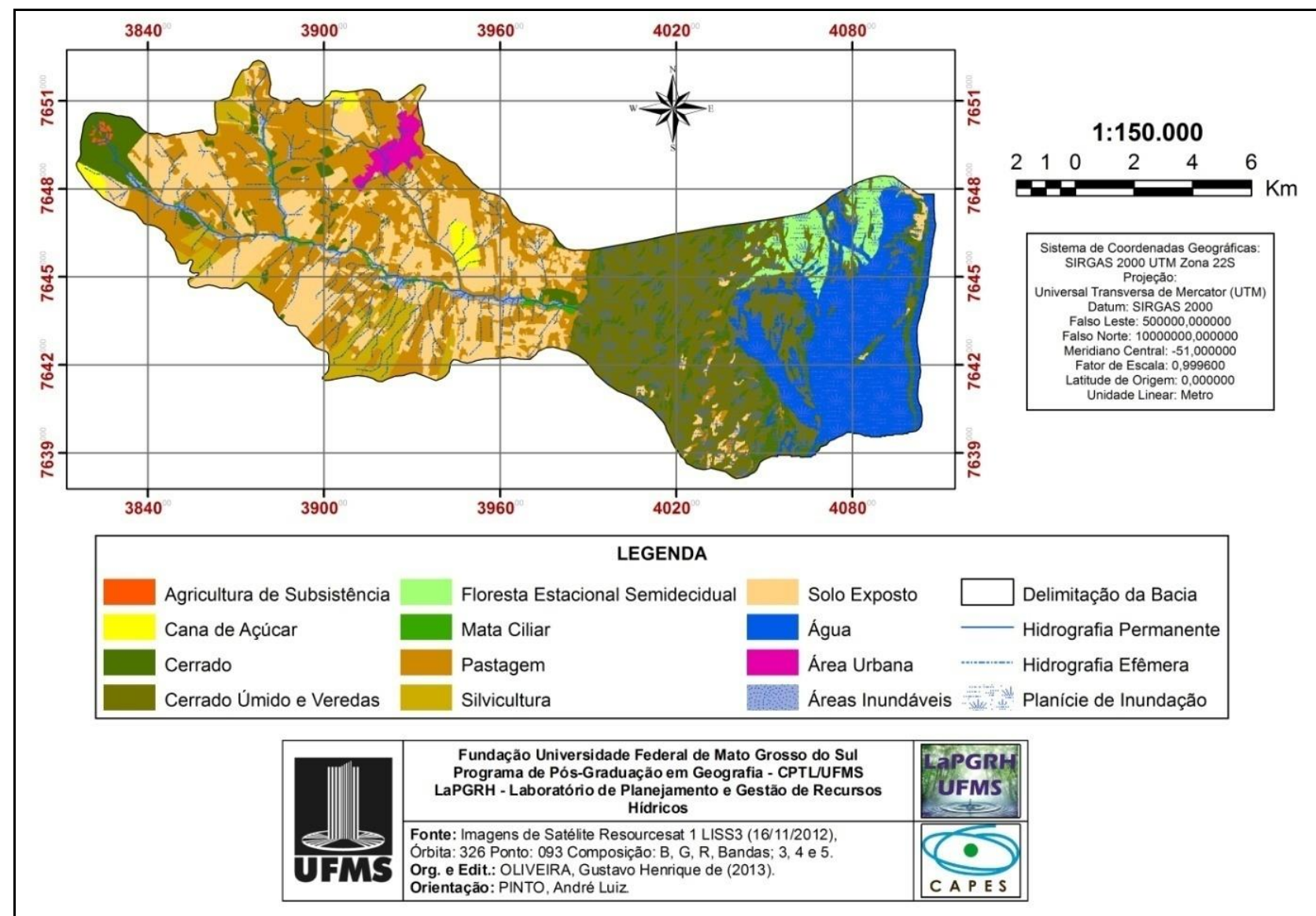

Figura 03: Carta de Uso e Ocupação da Terra na Bacia do Córrego Bom Jardim, Brasilândia/MS do ano de 2012.

A tabela 06 representa quantitativamente cada tipo de uso e ocupação da terra no ano de 2012 na bacia, onde podemos verificar que as áreas de cerrado nativo e matas ciliares representam apenas $8,67 \%$ juntas, fato que se deve as grandes áreas de pastagens plantada e outros tipos de agricultura. 
Há de se ressaltar inclusive que algumas manchas agrupadas que representam o solo exposto, recobrem um área de 20,30\%, número este alarmante se comparado com os demais usos na bacia, pois na maior parte ou quase toda desse solo em exposição não é realizado nenhum tipo de prática conservacionista de manejo e uso da terra.

Tabela 06: Uso, Ocupação e Manejo da Terra em 2012 na Bacia do Córrego Bom Jardim, Brasilândia/MS

\begin{tabular}{|c|c|c|c|c|c|c|}
\hline \multicolumn{7}{|c|}{ Uso, Ocupação e Manejo da Terra em 2012} \\
\hline \multirow{2}{*}{ Tipo de Uso e Manejo da Terra } & \multicolumn{2}{|c|}{ Área } & \multicolumn{2}{|c|}{ Manejo } & \multirow{2}{*}{$\begin{array}{l}\text { Fragilidade } \\
\text { Ambiental }\end{array}$} & \multirow{2}{*}{ Pesos } \\
\hline & $\mathrm{Km}^{2}$ & $\%$ & $\mathrm{Km}^{2}$ & $\%$ & & \\
\hline Agricultura de Subsistência & 0,26 & 0,13 & 0,00 & 0,00 & Muito Alta & 5 \\
\hline Água & 29,56 & 15,25 & 0,00 & 0,00 & Muito Alta & 5 \\
\hline Área Urbana & 2,32 & 1,20 & 0,00 & 0,00 & Muito Alta & 5 \\
\hline Áreas Inundáveis & 2,07 & 1,07 & 0,00 & 0,00 & Muito Alta & 5 \\
\hline Cana de Açúcar & 2,11 & 1,09 & 2,11 & 1,09 & Alta & 4 \\
\hline Cerrado & 15,55 & 8,02 & 9,59 & 4,95 & Baixa & 2 \\
\hline Cerrado Úmido e Veredas & 40,11 & 20,69 & 40,11 & 20,69 & Muito Baixa & 1 \\
\hline Floresta Estacional Semidecidual & 6,04 & 3,12 & 6,04 & 3,12 & Muito Baixa & 1 \\
\hline Mata Ciliar & 1,26 & 0,65 & 0,03 & 0,02 & Muito Baixa & 1 \\
\hline Pastagem & 47,58 & 24,54 & 4,48 & 2,31 & Alta & 4 \\
\hline Silvicultura & 7,65 & 3,95 & 7,65 & 3,95 & Média & 3 \\
\hline Solo Exposto & 39,35 & 20,30 & 20,16 & 10,40 & Muito Alta & 5 \\
\hline TOTAL & 193,86 & 100,00 & 90,17 & 46,51 & & \\
\hline
\end{tabular}

Org.: Oliveira (2013).

A figura 04 representa o mapa síntese do trabalho, onde foram cruzados os dados provenientes do mapeamento de Fragilidade Potencial com os do mapeamento de Uso e Ocupação da terra de 2012. 


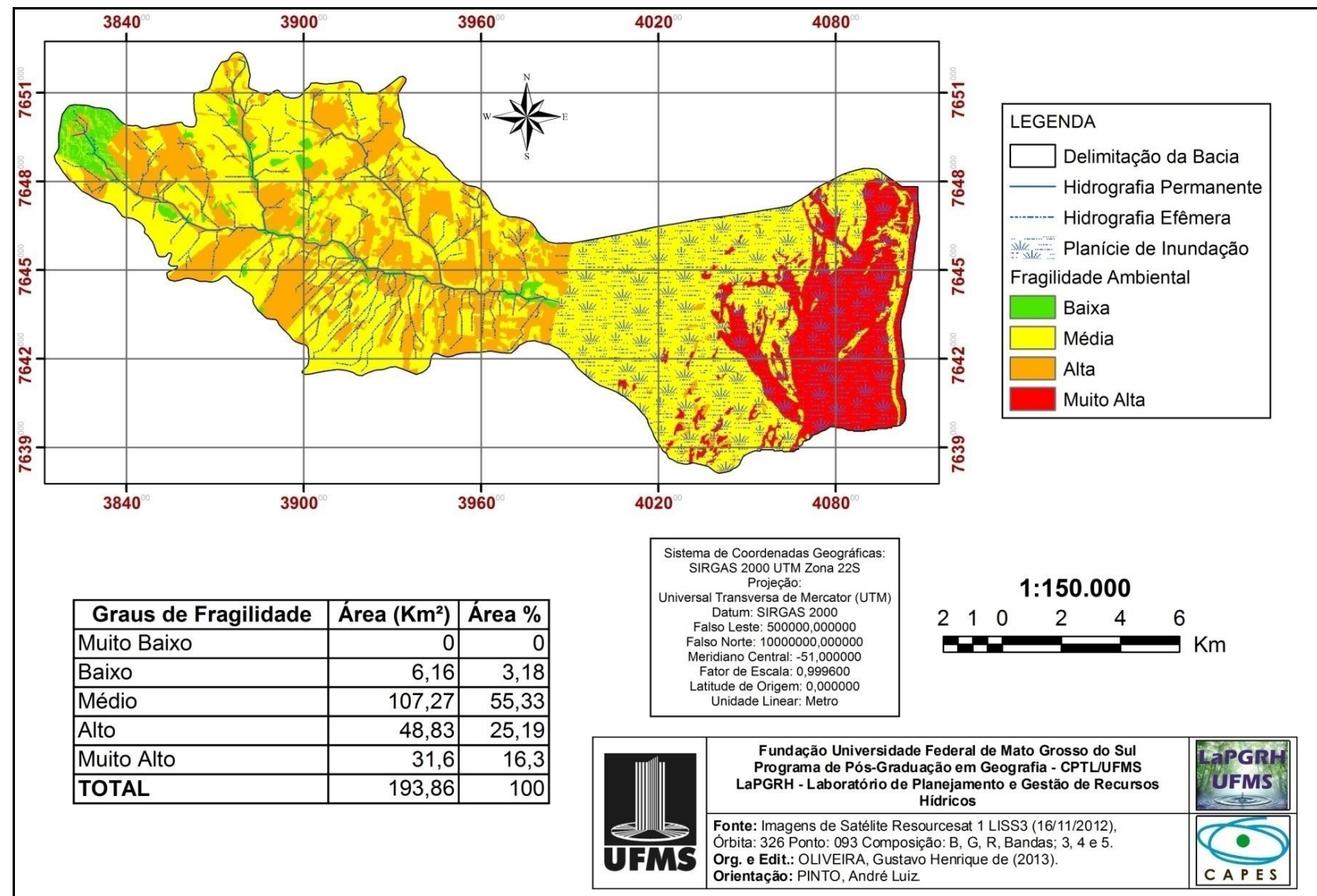

Figura 04: Mapa de Fragilidade Ambiental da Bacia do Córrego Bom Jardim, Brasilândia/MS.

Os resultados obtidos no cruzamento de dados para chegar a carta de Fragilidade Ambiental estão dispostos no quadro 03 mostrando assim as classes indicadas pelo mapeamento.

De maneira geral, mais da metade da bacia (55,33\%) enquadrou-se na classe de Fragilidade Ambiental Média, enquanto que a classe mais preocupante na bacia, a classe de Fragilidade Muito Alta recobre $16,30 \%$ que em sua maioria é composta por ambiente permanentemente inundado por se tratar de uma planície de inundação.

Quadro 03: Fragilidade Ambiental da Bacia Hidrográfica do Córrego Bom Jardim, Brasilândia/MS.

\begin{tabular}{|r|l|r|r|}
\hline Cor & Fragilidade Ambiental & Área $\mathbf{( K m}^{\mathbf{2}}$ ) & Área (\%) \\
\hline & Muito Baixa & 0 & 0 \\
\hline & Baixa & 6,16 & 3,18 \\
\hline & Média & 107,27 & 55,33 \\
\hline & Alta & 48,83 & 25,19 \\
\hline Muito Alta & 31,6 & 16,30 \\
\hline \multicolumn{2}{|c|}{ Total } & 193,86 & 100,00 \\
\hline
\end{tabular}

Org.: Oliveira (2013). 
A classe de Fragilidade Muito Baixa não apareceu no mapeamento, fato este devese aos pesos atribuídos à cada um dos fatores presentes em cada mapeamento que constitui o mapeamento final, pois os mesmos enquadraram-se poucas vezes na classe muito baixa de Fragilidade Potencial.

\section{CONSIDERAÇÕES FINAIS}

Diante dos resultados analisados sobre a temática de fragilidade, conclui-se, portanto, que o cruzamento de dados obtidos através de mapeamentos temáticos são de extrema importância para o entendimento dos processos físicos que ocorrem em bacias hidrográficas bem como auxilia na tomada de decisões no âmbito do planejamento e gestão de bacias.

O modelo proposto por Ross (1994) e Crepani et al., (2001) proporciona informações importantes para o planejamento do manejo dos diferentes tipos de uso e ocupação da terra e de praticas conservacionistas a serem aplicadas nos ambientes dispostos de cursos d'água.

Conclui-se, portanto que a metodologia utilizada, quando trabalhada paralelamente ao monitoramento anual ou sazonal é extremamente eficiente, tanto para a avaliação de possíveis impactos ambientais, quanto ao quantitativo pluviométrico e mensuração de ambientes mais frágeis. A fragilidade ambiental da bacia mostrou-se um zoneamento extremamente eficiente, porém depende na prática de inúmeras variáveis: precipitação, uso, ocupação e manejo da terra, profundidade e variação no nível freático, composição dos materiais inconsolidados, as quais devem ser levadas em consideração com restrições, dependendo da característica dos ecossistemas. A dificuldade de se colocar esta metodologia em prática, é que as Prefeituras Municipais não dispõem de informações de seus municípios em escala de detalhamento para seus planos, diretores de manejo e gestão e também pela pouca importância dada a estes tipos de pesquisas que são geradas a baixo custo e com certa facilidade.

\section{REFERÊNCIAS BIBLIOGRÁFICAS}


ARAUJO, G. H. S.; ALMEIDA, J.R. de; GUERRA, A. J. T. Gestão Ambiental de Áreas Degradadas. São Paulo - SP. Bertrand Brasil, 2005, p. 24.

BRASIL. Ministério do Meio Ambiente. Secretaria dos Recursos Hídricos e da Amazônia Legal. Política Nacional de Recursos Hídricos. Brasília, DF, 1997.

BRASIL, Ministério das Minas e Energias. Secretaria Geral. Projeto RADAMBRASIL: Geologia, Geomorfologia, Pedologia, Vegetação e Uso potencial da terra. Rio de Janeiro, 1982. Folha SE. 21 Campo Grande.

BRASIL. Áreas Prioritárias para Conservação, Uso Sustentável e Repartição de Benefícios da Biodiversidade Brasileira: Atualização - Portaria MMA n`9, de 23 de janeiro de 2007. / Ministério do Meio Ambiente, Secretaria de Biodiversidade e Florestas. - Brasília: MMA, 2007.

Câmara, G.; Monteiro, A. M. V.; Medeiros, J. S. Fundamentos epistemológicos da ciência da geoinformação. In: CÂMARA, G.; DAVIS, C.; MONTEIRO, A. M. V. (Orgs). Introdução à ciência da geoinformação. Disponível em: <http://www.dpi.inpe.br/gilberto/livro/introd>. Acesso em: 21, outubro, 2012.

CREPANI, E.; MEDEIROS, J. S. DE; HERNANDEZ, P.; FLORENZANO, T.G.; DUARTE, V.; BARBOSA, C. C. F. 2001. Sensoriamento Remoto e Geoprocessamento Aplicados ao Zoneamento Ecológico-Econômico e ao Ordenamento territorial. São José dos Campos. SAE/INPE.(INPE-8454-RPQ/722).

CHRISTOFOLETTI, A. Geomorfologia fluvial. São Paulo: Edgard Bluncher, 1981

CARVALHO, E. M.; PINTO, S. A. F. Avaliação do potencial natural de erosão da bacia do córrego João Dias,Aquidauana, MS. In: 3o Simpósio de Geotecnologias no Pantanal.Cáceres, MT. Embrapa Informática Agropecuária/INPE, 2010. P. 666 - 675. 
EMPRESA BRASILEIRA DE PESQUISA AGROPECUÁRIA - EMBRAPA. Centro Nacional de Pesquisa de Solos. Sistema brasileiro de classificação de solos. 2.ed. Rio de Janeiro, 2006. 306p.

EMPRESA BRASILEIRA DE PESQUISA AGROPECUÁRIA - EMBRAPA/CPAO. Centro Nacional de Pesquisa de Solos. Dourdos, 2013.

ESRI 2011. ArcGIS Desktop: Release 10. Redlands, CA: Environmental Systems Research Institute

MATO GROSSO DO SUL Atlas Multirreferêncial. Secretaria Estadual de Planejamento e Coordenação Geral. Geologia. Campo Grande, 1990, p.10.

PINTO, A. L.; LORENZ S., J. L.; FERREIRA, A. G.: BASSO, P. M.; GRECHIA, L.: OLIVEIRA, G. H.; PEREIRA, G. A. Subsidio Geológico/Geomorfológico ao ordenamento do uso, ocupação e manejo do solo, visando a redução da perda de solo e a recuperação da qualidade das águas superficiais da Bacia do Córrego Bom Jardim, Brasilândia/MS. Relatório Final FUNDECT/MS. UFMS. Três Lagoas, 2010, 242p.

PLANO DE MANEJO PARA RESERVA CISALPINA. Relatório encomendado pela CESP. Departamento de Meio Ambiente. São Paulo, outubro de 2007, 173 p.

ROSS, J. L. S. Análise empírica da fragilidade dos ambientes naturais e antropizados. Revista do Departamento de Geografia. n.8, p.63-74. 1994. 